\title{
Reflexões Sobre Ciência
}

\section{Introdução}

Vivemos numa época marcada pelas conquistas científicas e tecnológicas. Em nenhum outro momento da história, a humanidade compreendeu a natureza de forma tão profunda. Em nenhum outro momento da história, a humanidade explorou a natureza de forma tão intensa. Ciência e tecnologia andam de mãos dadas. Quanto maior o conhecimento científico, mais e melhores tecnologias poderão ser desenvolvidas. Quanto mais tecnologia, mais e melhores serão as possibilidades de pesquisas científicas. Além disso, quanto mais desenvolvermos o conhecimento científico, mais nos desenvolveremos enquanto sociedade humana. Lembremos que toda civilização pré-científica sempre imaginou a Terra parada e o Sol girando em torno de nós. Apenas com o advento da ciência, que a humanidade foi capaz de perceber que, na realidade, o que ocorre é justamente o contrário. Ou seja, o desenvolvimento científico muda a sociedade, tanto tecnológica quanto intelectualmente.

Do ponto de vista histórico, apenas recentemente, chegamos a um nível robusto, profundo e consistente de conhecimento sobre a natureza. Por exemplo, boa parte da comunicação mundial é realizada, explorando-se as propriedades das ondas eletromagnéticas. Contudo, o conceito de onda eletromagnética surgiu na Terra apenas em 1864, quando James C. Maxwell apresentou sua teoria onde apresentou a possibilidade de campos elétricos e magnéticos se propagarem, de forma acoplada, como uma onda. Antes de 1864, ninguém jamais imaginou, de forma sistemática, qualquer suposição do tipo.

Sabemos que, ao longo de muitas gerações, as espécies são mutáveis e, com isso, novas espécies podem ser criadas. O principal responsável pela introdução de tal ideia foi Charles R. Darwin, sendo seu principal trabalho, o livro "A Origem das Espécies", publicado em 1859. Atualmente, estudamos no colégio a forma em dupla hélice do DNA, e como, a partir desse formato, uma célula realiza o processo de duplicação do material genético. Lembremos que esse modelo foi proposto por James D. Watson e Francis H. C. Crick apenas em 1953, pouco mais de meio século atrás. A lista de descobertas revolucionárias e novas, menos de dois séculos, é extensa. Majoritariamente, o estágio atual da ciência e da tecnologia foi desenvolvido nesse período.

Paralelamente, e talvez paradoxalmente, a partir dos últimos dez ou vinte anos, nossa época também tendo sido marcada por um crescente distanciamento do espírito científico. Aparentemente, a massificação do acesso à informação, gerada com o advento da internet, tem ajudado a ampla disseminação de informações sobre, literalmente, tudo. Nesse contexto, o conhecimento científico, histórico e arduamentemente construído, é apresentado quase que em pé de igualdade com informações com pouco, ou nenhum, embasamento, causando uma pseudoconfusão entre fatos e opniões. A própria noção de ciência, em muitos casos, tem sido apresentada de forma leviana. Fakenews são apenas uma parte, talvez pequena, das consequências negativas resultantes desse processo. Tudo isso tem contríbuído para uma sensação de desconfiança generalizada na sociedade moderna. Reforçando a ideia de uma sociedade líquida (utilizando a metáfora do sociólogo Zygmunt Bauman).

Pensando em apresentar um norte, principalmente aos alunos dos cursos de graduação, compilamos reflexões sobre o que é ciência, o método científico, a construção do conhecimento científico, a verdade cientíca e pontos correlatos. As reflexões apresentadas aqui são de renomados cientístas da atualizade, ou seja, como a ciência é vista pelos grandes cientistas? Pensamos que as melhores pessoas para guiarem uma reflexão sobre ciência são justamente os grandes cientistas. Neste trabalho, definimos como cientista da atualidade aquele que desenvolve, ou densenvolveu, trabalho científico nas últimas três décadas.

Acreditamos que as reflexões apresentadas aqui são representativas da comunidade científica internacional. 
Embora sejam representativas, é importante notar que elas, provavelmente, não perfazem consenso total, e, com certeza, não exaurem o tema em questão. Selecionamos cinco textos de cientístas de áreas distintas: Bioquímica, Física, Química, Biologia e Astronomia. Optamos por escolher textos que enfatizam espectos complementares, de forma a tentar obter uma certa fluidez entre os escritos. Em todos os casos, retiramos algumas passagens do texto original. Esperamos que o leitor busque pelos trabalhos originais, os quais estão indicados nas referências.

\section{Os Autores}

Nossa primeira reflexão foi extraída do início do monumental "Princípios de Bioquímica de Lehninger"," cujos autores são David L. Nelson e Michael M. Cox. O livro em questão é mundialmente adotado como material didático em disciplinas de bioquímica e correlatas. Nelson obteve o doutorado em Bioquímica pela Stanford Medical School e realizou pós-doutorado na Harvard Medical School. Em 1971, Nelson ingressou na University of WisconsinMadison, tornando-se professor catedrático de bioquímica em 1982. Já Cox obteve o doutorado na Brandeis University e realizou o pós-doutorado em Stanford. Ele mudou-se para a University of Wisconsin-Madison em 1983, tornando-se professor catedrático de bioquímica em 1992. Por quase três décadas, ambos têm lecionado cursos relacionados à bioquímica para estudantes de graduação e pós-graduação.

A segunda reflexão foi extraída do capítulo 1 do célebre "Curso de Física Básica" de H. Moysés Nussenzveig. ${ }^{2} \mathrm{O}$ livro é adotado nacionalmente como material didático nos cursos de Física e correlatos. Nussenzveig doutorou-se em Física em 1957 pela Universidade de São Paulo. Realizou pós-doutorado pela University of Birmingham (Inglaterra), pelo Eidgenossische Technische Hochschule (Suiça), pela University of Utrecht (Holanda) e pela Technical University Eindhoven (Holanda). Ele é Professor Emérito da UFRJ, Fellow da American Physical Society, da Optical Society of America e da TWAS, Prêmio Max Born da Optical Society of America, Prêmio Nacional de Ciência e Tecnologia, GrãCruz da Ordem Nacional do Mérito Científico e membro titular da Academia Brasileira de Ciências.

O próximo texto vem do prólogo do livro "On Being: A scientist's exploration of the great questions of existence" de Peter Atkins. ${ }^{3}$ Atkins é também autor dos livros "Físicoquímica" e "Química Inorgânica", mundialmente adotados como material didático nos cursos química e correlatos. Ele doutorou-se em Química em 1964 pela University of Leicester e realizou pós-doutorado na University of California. Em 1969, ganhou a Medalha de Honra da Royal Society of Chemistry. Foi professor de Físico-química na Oxford University até se aposentar em 2007.

A quarta reflexão foi escrita por Richard Dawkins, sendo extraída de seu livro "O Capelão do Diabo", Capítulo 2 “O que é verdade?". ${ }^{4} \mathrm{O}$ livro em questão é uma coletânea de ensaios sobre temas como darwinismo, ética na ciência, alimentos transgênicos, medicinas alternativas, pósmodernismo, religião, educação, dentre outros. Dawkins é mundialmente conhecido por seus livros de divulgação científica, tais como "O Gene Egoísta" e "O Relojoeiro Cego". Ele doutorou-se em zoologia em 1966 pela Oxford University. Nessa universidade, ele foi Professor Para a Compreensão Pública da Ciência de 1995 a 2008.

Nossa última reflexão foi obtida a partir da degravação da última entrevista concedida por Carl Sagan, ${ }^{5}$ a entrevista pode ser assistida no portal do youtube. Sagan é mundialmente reconhecido por ter sido um grande divulgador da ciência. Ele escreveu vários livros, como "Os Dragões do Éden" e "Contato", além de ter sido coautor e apresentador da série de televisão "Cosmos: Uma Viagem Pessoal". Sagan doutorou-se em astronomia em 1960 pela University of Chicago. Por vários anos, ele foi professor de astronomia na Cornell University, onde também foi diretor do Laboratório Para Estudos Planetários.

\section{Reflexões Sobre Ciência}

\section{DAVID L. NELSON E MICHAEL M. COX}

(...) Ciência é tanto um modo de pensar sobre o mundo natural como a soma das teorias e informações que resultam desse pensamento. O poder e o sucesso da ciência resultam diretamente da confiança nas ideias a serem testadas: informação sobre fenômenos naturais que podem ser observados, medidos e reproduzidos, além de teorias que têm valor prognóstico. O progresso da ciência se baseia em uma suposição fundamental, muitas vezes, não explícita, mas crucial para a empreitada: a de que as 
leis que governam as forças e os fenômenos existentes no universo não estão sujeitos a mudanças. $\mathrm{O}$ ganhador do Prêmio Nobel, Jacques Monod, referiu-se a essa suposição como o "postulado da objetividade". Assim, o mundo natural pode ser compreendido, aplicando-se um processo de questionamento - o método científico. A ciência não poderia ter sucesso em um universo que nos pregasse peças. Diferentemente do postulado da objetividade, a ciência não faz nenhuma afirmativa inviolável sobre o mundo natural. Uma ideia científica útil é aquela que (1) tenha sido ou possa ser mensurada de maneira reproduzível e (2) pode ser utilizada para prever novos fenômenos de maneira precisa.

(...) O método científico é, na realidade, uma coleção de caminhos, todos levando a uma descoberta científica. No caminho da hipótese e experimentação, o cientista levanta uma hipótese e a submete a um teste experimental. Muitos processos, com os quais os bioquímicos trabalham todos os dias, foram descobertos dessa maneira. A estrutura do DNA elucidada por James Watson e Francis Crick levou à hipótese de que os pares de bases constituíam a base para a transferência de informações na síntese de polinucleotídeos(...).

Watson e Crick produziram sua estrutura do DNA, por meio de um processo de construção de modelo e cálculo. Não houve experimento real envolvido, embora a construção do modelo e os cálculos realizados tenham utilizado dados coletados por outros cientistas. Muitos cientistas aventureiros aplicaram o processo de exploração e observação como um caminho para a descoberta. Viagens históricas de descoberta (entre elas a de Charles Darwin no H.M.S. Beagle, em 1831) ajudaram no mapeamento do planeta, na catalogação dos seres vivos, e modificaram a forma como encaramos o mundo. (...) Um processo análogo ao da hipótese e experimentação é o da hipótese e dedução. Crick fundamentou que deveria existir uma molécula adaptadora que facilitasse a tradução da informação do RNA mensageiro em proteína(...).

Nem todos os caminhos para a descoberta envolvem planejamento. Frequentemente, a sorte também faz sua parte. A descoberta da penicilina por Alexander Fleming, em 1928, e dos RNA catalisadores, por Thomas Cech, no início dos anos 1980, foram feitas por um golpe de sorte, embora alcançadas por cientistas bem preparados para explorá-las(...).
Esses diversos caminhos que levam à descoberta científica podem parecer um tanto diferentes, mas têm importantes aspectos em comum. Eles se concentram no mundo natural. Baseiam-se na observação e/ou experimentação reproduzíveis. Todas as ideias, palpites e fatos experimentais que se originam dessas empreitadas podem ser testados e reproduzidos por cientistas em qualquer lugar do mundo. Todos podem ser utilizados por outros cientistas para construir novas hipóteses e fazer novas descobertas. Todos levam à informação, que é incluída apropriadamente no mundo da ciência. (...) Nenhuma jornada humana é mais empolgante e potencialmente recompensadora do que a tentativa, às vezes bem-sucedida, de compreender parte do mundo natural.

\section{H. MOYSÉS NUSSENZVEIG}

Faremos apenas algumas observações sobre o método científico.

1. Observação e experimentação: são o ponto de partida e ao mesmo tempo o teste crucial na formulação das leis naturais. (...) O bom acordo com a experiência é o juiz supremo da validade de qualquer teoria científica. Assim, o diálogo Hegeliano: "Só pode haver sete planetas. - Mas isso contradiz os fatos! - Tanto pior para os fatos!" representa o oposto da atitude científica. A única autoridade reconhecida como árbitro decisivo da validade de uma teoria é a verificação experimental de suas consequências. Entretanto, "embora a ciência se construa com dados experimentais, da mesma forma que uma casa se constrói com tijolos, uma coleção de dados experimentais ainda não é ciência, da mesma forma que uma coleção de tijolos não é uma casa" (Poincaré).

2. Abstração, indução: Já se disse que a primeira lei da ecologia é: "Tudo depende de tudo"; é por isso que problemas ecológicos são tão complexos. Em certa medida, o mesmo vale para a física ou qualquer outra ciência natural. Quando uma maçã cai da árvore, o movimento da Terra sofre uma (pequeníssima!) perturbação, e ele também é afetado pelo que acontece em galáxias extremamente distantes Entretanto, seria impossível chegar a formulação de leis naturais se procurássemos levar em conta 
desde o início, no estudo de cada fenômeno, todos os fatores que possam influenciá-lo, por menor que seja essa influência. O primeiro passo no estudo de um fenômeno natural consiste em fazer abstração de grande número de fatores considerados inessenciais, concentrando a atenção apenas nos aspectos mais importantes. O julgamento sobre o que é ou não importante já envolve a formulação de modelos e conceitos teóricos, que representam, segundo Einstein, uma "livre criação da mente humana". Uma vez atingido certo estágio no desenvolvimento de conceitos e modelos, podese procurar, por meio de um processo indutivo, formular leis fenomenológicas, ou seja, obtidas diretamente a partir dos fenômenos observados, como forma sintética e mais econômica de descrevêlos. Convém frisar que este é apenas um de muitos processos possíveis que têm sido empregados na formulação de leis físicas.

3. Leis e teorias físicas: (...) Uma boa teoria: a) Deve ser capaz de reduzir grande número de fenômenos diversos a um pequeno número de leis simples, mostrando que podem ser deduzidos matematicamente a partir dessas leis básicas; b) Deve ter poder preditivo: a partir das leis básicas, deve ser possível predizer fenômenos novos que possam ser comparados com a experiência. Uma teoria deve sempre ser explorada em todas as direções possíveis, no sentido de verificação de suas previsões. Um dos maiores triunfos da teoria da gravitação universal foi a predição da existência de Netuno, feita por Adams e Leverrier em 1846.

4. Domínio de validade: Todas as teorias físicas conhecidas sempre têm representado aproximações aplicáveis num certo domínio da experiência. Assim, por exemplo, as leis da mecânica clássica são aplicáveis aos movimentos usuais de objetos macroscópicos, mas deixam de valer: (i) para velocidades comparáveis com a velocidade da luz, quando aparecem efeitos relativísticos; (ii) para objetos na escala atômica, quando temos de empregar a mecânica quântica. Entretanto, uma "revolução científica" raramente inutiliza por completo as teorias precedentes. A validade aproximada dessas teorias no domínio em que já haviam sido testadas experimentalmente garante, em geral, sua sobrevivênvia nesse domínio. Assim, a mecânica clássica continua sendo aplicável a uma grande variedade de movimentos macroscópicos.

Uma nova teoria representa em regra uma generalização da antiga, estendendo-a a um domínio mais amplo, mas contendo-a, muitas vezes, como caso particular ou caso limite, válido aproximadamente no domínio anterior. Isto não impede que os conceitos básicos da nova teoria possam diferir radicalmente dos anteriores.

O processo de "seleção natural", pelo qual passam as teorias científicas, exige que sejam sempre submetidas a uma ampla crítica pela comunidade científica internacional e ao maior número possível de testes experimentais. Por isso, o segredo e o dogma são inimigos da ciência e a liberdade de comunicação e de pesquisa são vitais para o seu florescimento.

\section{PETER ATKINS}

O método científico pode iluminar todos e quaisquer conceitos, mesmo aqueles que têm incomodado a humanidade desde os primeiros lampejos da consciência e continuam a fazê-lo ainda hoje. Ele pode elucidar o amor, a esperança e a caridade. Pode elucidar também as grandes inspirações para a realização humana, os sete pecados capitais: orgulho, inveja, raiva, ganância, preguiça, gula e luxúria (...).

(...) O método científico emergiu surpreendentemente tarde na história humana. A humanidade levou vários milhares de anos até tropeçar no modo muito simples, e para nós agora um tanto óbvio, de descobrir o cerne das coisas: fazer observações e então comparar as anotações. Claro, existem sofisticações de ambos os componentes, a ciência não é uma simples caminhada jovial pela natureza. (...). As observações não podem ser deixadas soltas ao vento, sendo influenciadas por parâmetros incontroláveis: elas devem ser focadas e isoladas. As observações também não podem ser apenas a recitação de pré-conceitos e pré-concepções: elas devem ser experimentos. As comparações de anotações não podem ser conversas vazias: escrutínios minuciosos e avaliações por peritos especialistas é a ordem do dia. Às vezes, por descuido do revisor ou engano do revisado, erros, 
intencionais ou não, escapam à luz da intensa inspeção mas, nunca por muito tempo, para o escrutínio minucioso o tempo é infinito. De fato, quanto mais extravagante for a afirmação, quanto mais revolucionário será o pensamento, assim mais intensa será a pressão sobre a sua avaliação.

Então, há o extraordinário casamento entre observação e matemática. A humanidade (...) desenvolveu uma robusta linguagem de extremo rigor e austeridade que mostrou-se ser uma ferramenta perfeita para exprimir objetivamente as consequências de um salto imaginativo e qualitativo. Em outras palavras, a humanidade adicionou a espinha dorsal a uma fantasia, para que esta possa suportar a aspereza da comparação quantitativa da predição com a observação (...).

Nem toda a ciência, no entanto, avança montada na grande aliança entre experiência e matemática. Darwin não formulou sua teoria da seleção natural em termos de dispositivos matemáticos, ainda sim, ela tem um poder extraordinário. Suas ideias conduziram a aspectos da teoria que foram capazes de ser formulados matematicamente. Dessa forma, o poder da teoria foi amplamente estendido. Mas, em seu cerne, a seleção natural não é uma teoria matemática e ainda sim não lhe falta poder. De fato, é indiscutível que a teoria de seleção natural é uma das teorias mais poderosas dentre todas as teorias já propostas, de uma simples semente de ideia, uma grande floresta de consequências emerge.

Em poucas palavras, a ciência tem como princípio central a publicação compartilhada, a observação controlada, que chamamos de experimento, e, onde for apropriado, ela será guiada, melhorada e propagada pela austeridade do rigor da lógica matemática.

(...) Em suma, eu reafirmo minha alegação de que o método cientifico é o único meio de descobrir a realidade da natureza, embora suas interpretações atuais estejam abertas a revisão, a abordagem, fazer observações e comparar anotações, sobreviverão para sempre como a única maneira de se adquirir conhecimento confiável.

\section{RICHARD DAWKINS}

(...) Suponha que concordemos, por um momento, em tratar a verdade científica apenas como uma verdade entre várias outras, e a coloquemos lado a lado com todas as suas competidoras: a verdade trobriandesa, a verdade kikuyu, a verdade maori, a verdade inuíte, a verdade navajo, a verdade ianomâmi, a verdade Kung San, a verdade feminista, a verdade islâmica, a verdade hinduísta. A lista é interminável — e isso, por si só, já é uma observação reveladora.

Teoricamente, as pessoas poderiam abrir mão de sua fidelidade a uma "verdade" e mudar para uma outra qualquer cujo mérito considerassem maior. Mas com base em que elas o fariam? Por que razão alguém abandonaria, por exemplo, a verdade kikuyu, para abraçar a verdade navajo? Mudanças movidas por mérito são raras. Com uma exceção, de crucial importância. O único membro da lista que é capaz de regularmente persuadir os neófitos quanto à sua superioridade é a verdade científica. As pessoas são leais a outros sistemas de crença pela simples razão de que foram criadas daquela maneira e nunca chegaram a conhecer uma alternativa melhor. Quando elas têm a sorte de poder escolher, os médicos e outros profissionais do gênero prosperam, ao passo que os feiticeiros entram em declínio. Mesmo aqueles que não têm, ou não podem ter, uma educação científica optam por se beneficiar da tecnologia que a educação científica de outras pessoas tornou disponível. (...)

Basta de relativismo cultural. Um outro tipo de questionador enfadonho prefere deixar escapar o nome de Karl Popper ou (como está mais na moda) o de Thomas Kuhn:

"Não há verdade absoluta. Nossas verdades científicas não passam de hipóteses que ainda não foram refutadas, que acabarão por ser substituídas. No pior dos casos, as "verdades" de hoje, depois da próxima revolução científica, nos parecerão pitorescas e absurdas, se não realmente falsas. O melhor que os cientistas podem almejar é uma série de aproximações que progressivamente reduzem os erros, sem nunca chegar a eliminá-los.”

A importunação popperiana resulta em parte do fato acidental de que os filósofos da ciência são tradicionalmente obcecados por um episódio da história científica: a comparação entre as teorias da gravidade de Newton e de Einstein. É verdade que a lei do inverso do quadrado de Newton mostrou ser uma aproximação, um caso especial da fórmula mais geral de Einstein. Se conhecermos somente essa passagem da história da ciência, é bem possível que acabemos por concluir que todas as verdades aparentes são meras aproximações cujo destino é a substituição (...). 
Se eu estivesse sentado no banco das testemunhas e o promotor, apontando seu dedo austero na minha direção, perguntasse "É ou não é verdade que você estava em Chicago na noite do crime?", seguramente não perderiam muito tempo comigo caso eu respondesse: "O que você entende por 'verdade'? A hipótese de que eu estava em Chicago não foi refutada até o momento, mas é apenas questão de tempo antes que se possa ver que ela não passa de uma aproximação".

(...) É simplesmente verdadeiro que o Sol é mais quente que a Terra e que a escrivaninha na qual eu escrevo neste momento é feita de madeira. Essas não são hipóteses que aguardam refutação, nem aproximações temporárias de uma verdade sempre impalpável; também não são verdades locais que poderiam ser contestadas em uma outra cultura. E o mesmo se pode dizer com segurança em relação a muitas verdades científicas, ainda que não possamos vêlas "com os nossos próprios olhos". A dupla hélice do DNA será sempre verdadeira, assim como será sempre verdadeiro que, se você e um chimpanzé (ou um polvo ou um canguru) seguirem o rastro de seus antepassados até um ponto suficientemente longínquo, acabarão por encontrar um ancestral comum. Para os demasiado formalistas, essas são hipóteses que no futuro podem vir a ser refutadas. Mas elas jamais o serão. Estritamente falando, a verdade de que não havia seres humanos no período Jurássico ainda é uma conjectura, que poderia ser refutada a qualquer momento pela descoberta de um único fóssil autenticamente datado por uma bateria de métodos radiométricos. Pode ser que isso aconteça. Quer apostar? Mesmo que se trate de hipóteses nominalmente não comprovadas, essas afirmações são verdadeiras, exatamente no mesmo sentido das verdades ordinárias da vida cotidiana; elas são verdadeiras no mesmo sentido em que é verdade que você tem uma cabeça e que a minha escrivaninha é de madeira (...).

(...) A física moderna nos ensina que a verdade não se limita ao que os nossos olhos podem ver, ou ao que pode ver a limitada mente humana, desenvolvida como ela foi para dar conta de objetos de tamanho médio movimentandose a velocidades médias ao longo de distâncias médias na África. Em face desses profundos e sublimes mistérios, os arroubos intelectuais equivocados dos pedantes da pseudofilosofia simplesmente não se mostram merecedores de nossa atenção.

\section{CARL SAGAN}

(...) não é que as pseudociências e supertições e as chamadas crenças da Nova Era ou o fundamentalismo são coisas novas. Eles estão conosco desde que somos humanos. Mas, vivemos numa era baseada em ciência e tecnologia, com formidáveis poderes tecnológicos.

(...) E se nós não as entendemos, e por "nós" eu quero dizer nós, o público em geral, se for algo do tipo "eu não sou bom nisso, não sei nada sobre", então quem está tomando todas as decisões sobre ciência e tecnologia que determinarão em que tipo de futuro nossos filhos viverão? Apenas alguns membros do congresso?

(...) Há dois tipos de perigo. Um é o que eu acabei de dizer. Que é criarmos uma sociedade baseada em ciência e tecnologia onde ninguém diz nada sobre ciência e tecnologia. Esta mistura combustiva de ignorância e poder, cedo ou tarde, vai explodir nas nossas caras. Quero dizer, quem está comandando ciência e tecnologia numa democracia onde o povo não sabe nada sobre isso?

E a segunda razão pela qual eu me preocupo com isso é que ciência é mais do que um corpo de conhecimento. É uma forma de pensar. Uma forma cética de interrogar o Universo, com pleno entendimento da falibilidade humana. Se nós não estamos aptos a fazer perguntas céticas para interrogar aqueles que nos dizem que algo, é verdade e sermos céticos quanto àqueles que são autoridade então estamos à mercê do próximo charlatão político ou religioso que aparecer. É aquilo que Thomas Jefferson enfatizou bastante. Não é o suficiente, dizia ele, exaltar certos direitos civis em uma constituição ou declaração de direitos. O povo tem que ser educado. E tem que praticar seu ceticismo e sua educação. De outra forma, nós não controlaremos o governo. O governo é que nos controlará.

(...) As pessoas conseguem ver as estatísticas do esporte. Olhe quantas pessoas podem fazer isso. Entender ciência não é mais difícil do que isso. Não envolve grandes atividades intelectuais. Mas, a questão sobre a ciência, primeiro de tudo, ela está atrás de como que o Universo realmente é. E não do que nos faz sentir bem. E muito das doutrinas opositoras está atrás do que nos faz sentir bem. E não do que é verdade.

(...) Vamos olhar mais profundamente. O que é fé? É a crença na ausência de evidência. Eu não pretendo dizer a ninguém em que acreditar. Mas, para mim, acreditar quando 
não há evidência persuasiva é um erro. A ideia é segurar a crença até que haja evidência persuasiva o bastante. E se o Universo não for de acordo com as nossas predisposições, então temos a obrigação de aceitar o Universo como ele realmente é.

(...) Deixe-me dizer. Religião lida com história, com poesia, com ótima literatura, com ética, com moral, incluindo a moralidade de tratar com compaixão os menos afortunados dentre nós. Todas estas coisas eu apoio totalmente. Onde a Religião se mete em encrenca são nos casos onde ela finge saber algo sobre ciência. A ciência na Bíblia, por exemplo, foi aprendida pelos judeus dos babilônios durate o cativeiro babilônico em 600 a.C. Era a melhor ciência do planeta, mas, nós aprendemos algumas coisas depois disso.

(...) Isto é parte de ser um humano. Os humanos tiveram este tipo de pensamento mágico por toda a nossa história. O problema é que hoje a tecnologia atingiu proporções formidáveis, talvez até incríveis, então os perigos de pensar desta forma são maiores. Não que isso seja uma coisa nova.

\section{Reflexões Finais}

Nossas reflexões iniciaram e terminaram com a ideia de que, fundamentalmente, ciência é uma forma cética e metódica de pensar e interrogar o Universo que vivemos. Existem caminhos diferentes para se chegar à descoberta científica, mas, como aponta Nelson e Cox: "Esses diversos caminhos que levam à descoberta científica podem parecer um tanto diferentes, mas têm importantes aspectos em comum. Eles se concentram no mundo natural. Baseiam-se na observação e/ou experimentação reproduzíveis.".

Ao longo dos caminhos, outro fator fundamental é a contrução de modelos abstratos para descreverem situações do mundo real. Segundo Nussenzveig: "O primeiro passo no estudo de um fenômeno natural consiste em fazer abstração de grande número de fatores considerados inessenciais, concentrando a atenção apenas nos aspectos mais importantes. O julgamento sobre o que é ou não importante já envolve a formulação de modelos e conceitos teóricos, que representam, segundo Einstein, uma 'livre criação da mente humana'.”.

A construção de modelos abstratos, quase sempre, de forma direta ou indireta, é baseada na robustez do rigor lógico da linguagem matemática. Como apontado por Atkins: "Então, há o extraordinário casamento entre observação e matemática. A humanidade (...) desenvolveu uma robusta linguagem de extremo rigor e austeridade que mostrou-se ser uma ferramenta perfeita para exprimir objetivamente as consequências de um salto imaginativo e qualitativo.". Lembremos a famosa frase de Galileu Galilei "A matemática é o alfabeto com o qual Deus escreveu o Universo".

Embora a ciência seja construída a partir de modelos abstratos e que novos modelos podem surgir. É importante enfatizar que, em geral, novos modelos não inutilizam os modelos anteriores nos domínios em que já haviam sido testados experimentalmente. Além disso, no estágio atual de desenvolvimento científico, existem modelos, ou aspectos de determinados modelos, com status de realidade objetiva, ou seja, algo que já é bem estabelecido e que representa uma "verdade científica". Como indica Dawkins: "É simplesmente verdadeiro que o Sol é mais quente que a Terra e que a escrivaninha na qual eu escrevo neste momento é feita de madeira. Essas não são hipóteses que aguardam refutação, nem aproximações temporárias de uma verdade sempre impalpável; também não são verdades locais que poderiam ser contestadas em uma outra cultura. E o mesmo se pode dizer com segurança em relação a muitas verdades científicas, ainda que não possamos vêlas 'com os nossos próprios olhos'. A dupla hélice do DNA será sempre verdadeira, assim como será sempre verdadeiro que, se você e um chimpanzé (ou um polvo ou um canguru) seguirem o rastro de seus antepassados até um ponto suficientemente longínquo, acabarão por encontrar um ancestral comum.".

Por fim, abordamos o aspecto social da ciência. O conhecimetno científico foi arduamente construído ao longo de séculos. Hoje, vivemos numa época marcada pelas conquistas científicas e tecnológicas, ciência e tecnologia andam de mãos dadas. A manutenção das instituições de pesquisa é feita, em grande parte, com dinheiro público. Ao mesmo tempo, os resultados desse empreendimento são partilhados, de forma desigual, na população. Nesse contexto, é imprescindível a educação científica na sociedade como um todo. Só assim, teremos condições de direcionar a sociedade rumo a um futuro melhor para todos, com desenvolvimento social e econômico. Como nos advertiu Sagan: "Se nós não estamos aptos a fazer 
perguntas céticas para interrogar aqueles que nos dizem que algo é verdade e sermos céticos quanto àqueles que são autoridade então estamos à mercê do próximo charlatão político ou religioso que aparecer.”.

\section{Referências}

1. Nelson, D. L.; Cox, M.M.; Princípios de Bioquímica de Lehninger. Título original: Lehninger principles of biochemistry. $6^{\circ} \mathrm{Ed}$., Artmed: Porto Alegre, 2014.

2. Nussenzveig, H. M.; Curso de Física Básica: Mecânica. $4^{\circ}$ Ed., Vol. 1, Blucher: São Paulo, 2002.

3. Atkins, P.; On Being: A scientist's exploration of the great questions of existence. Oxford University Press: Oxford, 2011.

4. Dawkins, R.; O Capelão do Diabo. Título do original: A Devil's Chaplain. Companhia das Letras: São Paulo, 2005.

5. Sagan, C.; Entrevista com Carl Sagan de 27 de maio de 1996. Disponível em: $<$ https://youtu.be/c2sJbjO3Vis $>$. Acesso em: 07 de maio de 2018.

\section{Ivo A. Marques*}

Universidade Federal de Goiás, Instituto de Física, Campus Samambaia, CEP 74690-900, Goiânia-GO, Brasil.

\section{*E-mail: ivo@ufg.br}

